\title{
BOITEMPO EDITORIAL E IVANA JINKINGS: UM QUARTO DE SÉCULO DE UMA EDITORA DE ESQUERDA NO BRASIL
}

\begin{abstract}
Ana Elisa Ribeiro ${ }^{1}$
Resumo: A questão mais ampla que nos move pode ser resumida na seguinte pergunta: Onde estiveram e onde estão narradas as mulheres editoras do Brasil? O viés de gênero, por sua evidente importância para a correção de narrativas que apagaram a atuação relevante de mulheres em vários campos, está na ordem do dia e na agenda de estudos, por exemplo, de sociologia da literatura (SAPIRO, 2016), e inspirada, ou informada, por estudos feministas anteriores. E enquanto esses estudos abordam também as estratégias de autor, vimos dando ênfase às estratégias e trajetórias de editoras (as casas e as mulheres), cujos estudos são ainda mais escassos, em especial no Brasil. A depender do nicho de atuação no mercado editorial, da região brasileira ou da época, será menos ou mais fácil encontrar as personagens desta história, infelizmente muito lacunar e carente de registros. Este artigo se vale de uma pesquisa documental no acervo digital do jornal Folha de S. Paulo para narrar as mais de duas décadas de existência da editora brasileira Boitempo Editorial, fundada pela paraense Ivana Jinkings, também editora e organizadora de obras do selo. Assumidamente uma editora de esquerda, mostramos, ao longo deste texto, sob uma mirada bourdiana, a trajetória da casa editorial por meio de autores, traduções, obras, coleções e parceiros, além de pontos de destaque como nichos (literatura e literatura infantil) e a relação com tecnologias digitais, já em anos mais recentes.
\end{abstract}

Palavras-chave: Ivana Jinkings; Boitempo; Mulheres Editoras; Produção Editorial.

\section{BOITEMPO EDITORIAL AND IVANA JINKINGS: A QUARTER CENTURY TRAJECTORY OF A LEFT-WING BRAZILIAN PUBLISHING HOUSE}

\begin{abstract}
The overall issue that moves us in this work can be summarized by the following questions: where have been the Brazilian women publishers and where have they been narrated? Due to its evident significance to the correction of narratives that erased the relevant contribution of women in various fields, the gender bias is in the order of the day and it is also present in
\end{abstract}

${ }^{1}$ Professora do Programa de Pós-Graduação em Estudos de Linguagens do Centro Federal de Educação Tecnológica de Minas Gerais. Doutora em Estudos Linguísticos pela UFMG. Agradeço a inestimável colaboração de Sérgio Karam (UFRGS) e à Fapemig, pelo apoio. 
the Sociology of Literature studies (SAPIRO, 2016), inspired or informed by previous feminist studies. While these studies also address author strategies, we have been giving emphasis to the strategies and trajectories of women publishers and their publishing houses, the objects of even more scarce studies, especially in Brazil. Depending on the niche of operation at the publishing market, on the specific region of Brazil or even on the period of time discussed, it will be less or more easy to find the characters of this history, one that is unfortunately full of gaps and almost devoid of records. Based in a documental research in the digital archives of the Brazilian newspaper Folha de S.Paulo, in this paper we presented more than two decades of the left-wing Brazilian publishing house Boitempo Editorial, founded by Ivana Jinkings, also its editor and author of some books. We show, under a Bourdian theory, its solid way with authors, translators, titles, collections and partners, besides highlighting some other aspects, like literary books, children books and the relation with digital technologies in more recent years. Based in a documental research in the digital archives of the Brazilian newspaper Folha de S.Paulo, in this paper we presented more than two decades of the left-wing Brazilian publishing house Boitempo Editorial, founded by Ivana Jinkings, also its editor and author of some books. We show, under a bourdian thoery, its solid way with authors, translators, titles, collections and partners, besides highlighting some aspects, like literary books, books for children and the relations with digital technologies, in more recent years.

Keywords: Ivana Jinkings; Boitempo; Women Publishers; Editorial Production.

\section{Algumas considerações iniciais}

A questão mais ampla que nos move pode ser resumida na seguinte pergunta: Onde estiveram e onde estão narradas as mulheres editoras do Brasil? O viés de gênero, por sua evidente importância para a correção de narrativas que apagaram a atuação relevante de mulheres em vários campos, está na ordem do dia e na agenda de investigações, por exemplo, de sociologia da literatura (SAPIRO, 2016), e inspirada, ou informada, por estudos feministas anteriores. E enquanto estes abordam também as estratégias de autor, vimos dando ênfase às estratégias e trajetórias de editoras (as casas e as mulheres), cujos estudos são ainda mais escassos, em especial no Brasil. A depender do nicho de atuação no mercado editorial, da região brasileira ou da época, será menos ou mais fácil encontrar as personagens desta história, infelizmente muito lacunar e carente de registros e análises. 
Temos um problema linguístico de saída, que termina por complexificar as buscas em arquivos, bancos de dados e mesmo em índices remissivos: a palavra editora, substantivo feminino, em português, é muito mais frequentemente aplicada às casas editoriais, às empresas que publicam livros. As mulheres editoras tiveram de ser redundantemente nomeadas aqui, a fim de distinguirmos bem as personagens de seu ofício ou de suas casas editoriais, quando foram, eventualmente, fundadoras, executivas ou editoras, num sentido curatorial, em suas trajetórias profissionais. Recorrendo à colossal obra O livro no Brasil, de Laurence Hallewell (2005), a fim de verificar momentos de nossa história editorial em que mulheres fossem mencionadas como editoras, o primeiro obstáculo que se impôs foi, justamente, a palavra editora, que geralmente nos leva a outros objetos. Para encontrar as personagens femininas de nossa história, provavelmente apagada ou à qual não é dada importância maior, foi necessário ler a obra de Hallewell e garimpar, nome a nome, as mulheres que porventura fossem mencionadas.

Outro elemento se insinuou como dificuldade ou como distrator nesta breve investigação: o eixo Rio-São Paulo costuma ser tratado como sinônimo de Brasil, o que talvez seja explicável e compreensível, mas também tem suas perversas implicações. É preciso que nos desviemos dessa "facilidade" e que nos voltemos a outras regiões, onde mulheres editoras podem ter atuado e atuam, a despeito da seletividade geográfica, que sempre distorce narrativas, enterrando ocorrências relevantes e diversas. No âmbito do projeto "Mulheres que editam: um mapeamento preliminar no Brasil", em execução no Programa de Pós-Graduação em Estudos de Linguagens do Centro Federal de Educação Tecnológica de Minas Gerais (CEFET-MG), temos empreendido esforços na busca de obras e/ou documentos que narrem trajetórias de mulheres editoras, no passado e no presente, cuidando de fazer algumas categorizações importantes para compreender em que circuitos elas atuaram e com que grau de dificuldade. Nosso recorte prioriza um circuito que consideramos mais complexo e mais árduo para mulheres, nos ofícios da edição: a literatura “de adultos”. Há outros círculos, também em nada fáceis, mas que contam com mulheres no comando há mais tempo e de maneira mais “aceitável”, como é o caso da literatura infantil e juvenil. Nenhuma dessas histórias é de se descartar; qualquer uma delas necessita, no mínimo, de registro e organização. 
Ana Elisa Ribeiro

\section{Uma editora}

Neste trabalho, por meio de pesquisa documental no acervo digital do jornal Folha de S.Paulo², reconstituímos, sob o viés de certo veículo de imprensa, ainda que de maneira breve, a trajetória da Boitempo Editorial, que se confunde com a história de sua fundadora, a editora Ivana Jinkings. Fundada em 1995, mesma década em que outras casas publicadoras passaram a existir no Brasil sob o pulso de mulheres ${ }^{3}$, a Boitempo conta 24 anos de atuação, tendo constituído um impressionante catálogo fundamentalmente de ideologias à esquerda, que inclui autores importantes de várias partes do mundo, além da publicação de literatura contemporânea, tanto estrangeira quanto brasileira. Fazem parte do catálogo da Boitempo Editorial, por exemplo, autores como Giorgio Agamben, Gyorgy Lukács, István Mészáros, Judith Butler, Slavoj Zizek e outros, muitas vezes em traduções diretas de suas línguas originais ${ }^{4}$. $\mathrm{O}$ aspecto da tradução é elemento central na atuação dessa editora, um dos critérios bourdianos (BOURDIEU, 2018[1999]) de análise de capital simbólico e econômico no campo editorial, muito embora deva ser profundamente repensado para o caso brasileiro.

A paraense Ivana Jinkings nasceu em Belém, em 1961, filha de Maria Isa Tavares e Raimundo Jinkings, intelectual comunista, fundador da primeira editora Boitempo, ainda na capital do Pará, e livreiro por mais de quatro décadas. A filha deu continuidade, de certa forma, à casa editorial do pai, em São Paulo, a partir de 1995, quando contava 34 anos. Antes disso, porém, passou por algumas editoras e periódicos, onde atuou como revisora e jornalista.

As origens da Boitempo mesclam a história paraense anterior do pai de Ivana Jinkings (certo elemento de herança, numa análise bourdiana), um famoso poema de Carlos Drummond de Andrade que dá nome à casa e um ato

\footnotetext{
${ }^{2}$ Nossa narrativa pauta-se em documentos disponíveis na web, como o site da própria Boitempo Editorial e especialmente o arquivo do jornal Folha de S.Paulo, explorado desde a primeira menção à palavra "boitempo", em 1960, até 2017, quando o periódico lançou suas mais recentes digitalizações. Também foi usado o termo "Ivana Jinkings", com muito menos ocorrências.

3 Para mencionar algumas: Rejane Dias, fundadora da Autêntica, de Minas Gerais; Zahidé Muzart e parceiras, na Mulheres, de Florianópolis; Rosa dos Tempos, de Rose Marie Muraro e parceiras, no Rio de Janeiro. É interessante anotar que Maria Mazarello, em Belo Horizonte, fundou a Mazza Edições, a fim de publicar autores negros(as), ela mesma negra, em 1981.

${ }^{4}$ Ver em <https://blogdaboitempo.com.br/catalogo_boitempo/> ou no site <https://www.boitempoeditorial.com.br/>, acessados em 13 jan. 2018.
} 
de publicação inaugural: em 1995, a Boitempo Editorial publicava o primeiro livro, Napoleão, de Stendhal. A partir daí, explicitada sua orientação marxista, Ivana Jinkings passou a atuar na procura, na seleção e na organização de livros para seu catálogo, o que desaguou também na compra de direitos de muitos livros de autores estrangeiros e traduções, trabalho respeitado especialmente no meio acadêmico, isso sem dispensar um "dispositivo institucional de decisão" (BOURDIEU, 2018[1999]) que incluiu parceiros e conselheiros na universidade e em outras instâncias de alto valor simbólico.

Nos arquivos da Folha de S.Paulo, as primeiras ocorrências de "boitempo", como é de se esperar, dizem respeito à obra do poeta Carlos Drummond de Andrade. No entanto, a partir de 1995, é a editora de Ivana Jinkings que monopoliza o termo, oferecendo centenas de ocorrências, em todos os anos, a partir de sua fundação. Curiosamente, no entanto, a primeira notícia aparece já em 13 de março de 1981, a respeito do lançamento de um livro de poemas de posseiros, no Pará, em uma parceria entre a Boitempo paraense e a Regional Norte da $\mathrm{CNBB}^{5}$. Depois, somente em 1996 a Boitempo de Ivana sai em nota ${ }^{6}$ sobre o lançamento de Luar, de Guy de Maupassant, terceiro volume de uma série lançada pela casa.

A partir de então, a Boitempo Editorial ganhou espaço em cadernos como Mais!, Ilustrada, Ilustríssima, Guia da Folha, Revista da Folha e até a Folhateen, além de notas ou colunas em cadernos de Economia e outros. Os textos dedicados às obras da editora são cada vez maiores, às vezes ocupando páginas inteiras e capas. Não raro, vários livros da Boitempo são notícia, ao mesmo tempo, no jornal do mesmo dia. Podem assim ser divisadas as relações da casa editorial (seus livros e sua dirigente) com a imprensa paulistana, com a Universidade de São Paulo, em especial, e com, obviamente, uma ideologia de esquerda bem orquestrada em suas publicações nacionais e traduzidas. Além dos livros, a Boitempo publica, desde 2003, uma revista, Margem Esquerda, como se pode ver, longeva. Por menor período, publicou um periódico intitulado Praga, também tema das primeiras notas na imprensa de alcance nacional.

${ }^{5}$ SCARPA, Paulo Sérgio. Posseiros publicam livro de poesias. Folha de S.Paulo, Especial, p. 24, 13 mar. 1981.

${ }^{6}$ FOLHA DE S.PAULO. Maupassant, Mais! 4 fev. 1996. 
Na maioria dos textos publicados na Folha, o foco recai sobre as obras e seus autores, quase nada sobre questões editoriais. Somente em alguns poucos casos, a própria editora, Ivana Jinkings, é enunciadora, especialmente em situações em que precisa responder publicamente pela editora (plágio, processos, etc.) ou quando a empresária lidera ações como feiras e a Liga Brasileira de Editoras (Libre ${ }^{7}$ ), que congregou e organizou pequenas e médias editoras brasileiras, no início dos anos 2000.

Em muitas ocasiões, é visível o planejamento desta casa editorial em relação a eventos, oportunidades que, além de serem lançamentos de livros, são debates, mesas-redondas ou conferências de nomes expressivos das letras, da academia ou autores estrangeiros em visita ao Brasil. Essa articulação dá à Boitempo visibilidade por meio da imprensa, caso da Folha. Em 1998, por exemplo, na celebração dos 150 anos do Manifesto Comunista, várias editoras preparavam livros ligados ao fato. A Boitempo publicava uma tradução do próprio Manifesto, organizada por Osvaldo Coggiola e acrescida de textos de Jean Jaurès e Lucien Martin, o que mereceu várias notas no jornal. Outras ocasiões mencionáveis são o Fórum Social Mundial, já nos anos 2000, com lançamentos e a vinda de István Mészáros, que rendeu muitas linhas de divulgação, em 2004; ou os 450 anos da cidade de São Paulo, quando um "arranha-céu de livros" foi publicado em homenagem à capital paulista, na expressão do jornalista Cassiano Elek Machado (que assinou muitas matérias sobre a editora $)^{8}$.

\section{Articulações editoriais - construção de espaço e identidade}

A Boitempo Editorial não se furtou de fazer parcerias. Em muitas ocasiões, publicou livros juntamente com outras casas, como a Ateliê Editorial, Edusp e institutos estrangeiros, além de estabelecer ligação com o Sesc e com outros espaços da cidade de São Paulo para eventos bastante noticiados. Também são inúmeras as resenhas e críticas aos livros da editora, e não apenas elogiosas, assinadas por jornalistas, mas principalmente por acadêmicos de renome. Em diversos casos, os mesmos livros são resenhados

\footnotetext{
${ }^{7}$ Ver situação atual em <http://libre.org.br/>. Acesso em 11 jan. 2018.

${ }^{8}$ MACHADO, Cassiano Elek. "SP 450 anos" deixa "arranha-céu" de livros. Folha de S.Paulo, Ilustrada, p. E3, 25 jan. 2005.
} 
mais de uma vez, por leitores diferentes, no mesmo ou em vários cadernos, como ocorre aos livros de Slavoj Zizek ou a alguns de literatura. É exemplar o caso das páginas da Revista da Folha de janeiro de 2004, na qual nada menos que cinco obras da Boitempo eram citadas e indicadas em notas: o perfil Adoniran - se o senhor não tá lembrado, de Flávio Moura e André Nigri; Ronda da meia-noite, de Sylvio Floreal; Eles eram muitos cavalos, de Luiz Ruffato; Brás - Sotaques e desmemórias, de Lourenço Diaféria (que seria finalista do Jabuti em 2004); e Vila Madalena - Crônica histórica e sentimental, de Enio Squeff.

A visibilidade da editora se realizou por meio de resenhas, mas também notas de lançamento, notícias, programação de eventos, entrevistas longas com autores da casa, excertos das obras publicados como "degustação" ou até notícias de obras que ainda estavam em produção. A partir de 2004, a Boitempo passou a figurar com alguma frequência em listas de mais vendidos e na seção Dez+, no caderno Mais!, ou na seção Cifras\&Letras, no caderno dedicado ao Mercado. É claro que esse tipo de seção e mesmo os cadernos mudam juntamente com a história dos jornais, que, por sua vez, estão intrinsecamente relacionados às práticas sociais. Entre os resenhistas dedicados aos textos da casa editorial estão Tom Zé, Luiz Tatit, Xico Sá, Marcelo Rubens Paiva, Octavio Ianni, Antonio Candido, Marilena Chauí, Luís Augusto Fischer, Joca Reiners Terron, Manuel da Costa Pinto, Luiz Ruffato, Cadão Volpato, Ronaldo Bressane, Nelson de Oliveira, Antonia Pellegrino, entre outros, em sua maioria homens, mesmo entre os jornalistas dedicados à cultura, o que merece atenção, pois faz notar o relativo silenciamento feminino também na crítica e no jornalismo cultural.

A coluna Painel das Letras, na segunda metade da primeira década dos anos 2000, assinada, em períodos diferentes, por Joselia Aguiar (excuradora da Festa Literária Internacional de Paraty, Flip), Maurício Meireles e Raquel Cozer, também foi frequente em dar notas sobre a Boitempo Editorial, seja para falar de seus lançamentos, seja para noticiar mudanças e decisões da casa. De modo semelhante, a coluna de Mônica Bergamo abria espaço para a casa de Ivana Jinkings.

Além dos lançamentos de livros de personalidades conhecidas e importantes para as ciências humanas, algumas polêmicas também rondaram 
a Boitempo, em todo caso trazendo visibilidade à casa. Em janeiro de 2005, por exemplo, Carlos Eduardo Lins da Silva ${ }^{9}$ assina uma resenha sobre o livro $A$ arte da entrevista, de Fábio Altman, em segunda edição, fazendo duras críticas à obra. No dia 20 de janeiro, a própria Ivana Jinkings responde às críticas na coluna Painel do Leitor, do Primeiro Caderno. Diz ela:

Carlos Eduardo Lins da Silva critica a falta de coesão do volume, que, longe de ter a intenção de ser um manual para estudantes de jornalismo, tem como principal mérito agrupar 48 excelentes exemplos de jornalismo. Organizado da forma mais lógica em casos assim - a cronológica -, a edição da Boitempo é fartamente ilustrada. Entrevistados e entrevistadores são "interpretados" pelos desenhos de Cassio Loredano. [...] Pode-se concordar ou não com os critérios dos resenhistas, mas fica evidente seu desprezo pelos desenhos, um gênero tão importante na imprensa." Ivana Jinkings, editora (SP)

Em outubro de 2008, Evando Nascimento, professor da Universidade Federal de Juiz de Fora, resenha ${ }^{10}$ o livro Cinismo e falência da crítica, de Vladimir Safatle (USP). Em 12 de outubro, o próprio Safatle responde às críticas ${ }^{11}$. Nascimento faz a tréplica em 19 do mesmo mês e Safatle responde bem ao lado ${ }^{12}$, com o que o jornal encerra o debate.

\section{Aniversários}

Uma trajetória como a da Boitempo, que continua nas mãos de Ivana Jinkings, mesmo em tempos de concentração editorial e oligopólios globais, tinha razões para celebrar seus aniversários decenais. Em 2005, a Folha noticiava a vinda de Michael Löwy ao Brasil ${ }^{13}$ para o $2^{\circ}$ Seminário Margem Esquerda, evento que comemorava os dez anos da casa editorial. Tal

\footnotetext{
${ }^{9}$ SILVA, Carlos Eduardo Lins. "A arte da entrevista" compõe mosaico sem coordenação. Folha de S.Paulo, 5 jan. 2005.

${ }^{10}$ NASCIMENTO, Evando. Bricolagem filosófica. Folha de S.Paulo, Mais!, p. 8, 5 out. 2008.

${ }^{11}$ SAFATLE, Vladimir. Conceito e ruptura. Folha de S.Paulo, p. 8, 12 out. 2008.

12 NASCIMENTO, Evando. Questão conceitual. Folha de S.Paulo, Mais!, p. 8, 19 out. 2008.

SAFATLE, Vladimir. Risco necessário. Folha de S.Paulo, p. 8, 19 out. 2008.

${ }^{13}$ FOLHA DE S.PAULO. O Capitalismo como religião. Mais!, p. 6, 8 set. 2005.
} 
Seminário voltou a ser divulgado em setembro, em matéria de Julián Fuks ${ }^{14}$ : "Trata-se de evento comemorativo pelos dez anos de existência da Boitempo, editora que, embora não seja a principal responsável pela difusão da vasta obra de Löwy, compartilha com ele muito de sua visão teórica, ideológica e política".

Anos mais tarde, na coluna Painel das Letras, Raquel Cozer noticiava a comemoração dos 20 anos da Boitempo ${ }^{15}$, em meio ao Seminário Internacional Cidades Rebeldes, com a participação de vários escritores e planos de oferecer dois cursos sobre autores de seu catálogo. Na mesma coluna $^{16}$, em setembro, a jornalista escreve:

Fundada em 1995, a Boitempo vai celebrar suas duas décadas de atividade de cara nova. O designer Gustavo Piqueira, da Casa Rex, prepara uma reformulação da identidade visual da editora - o que inclui, por exemplo, a atualização da logomarca e a criação de uma abreviatura dela, para ser usada na lombada dos livros.

A marca, já conhecida de um público cativo, sofre uma mudança não apenas de desenho, mas de aplicação, tornando-se uma espécie de flâmula nos livros.

Figuras 1, 2 e 3

Marcas da Boitempo Editorial, respectivamente, da esquerda para a direita: marca anterior aos 20 anos de existência da editora; marca para lombadas; e marca atual.

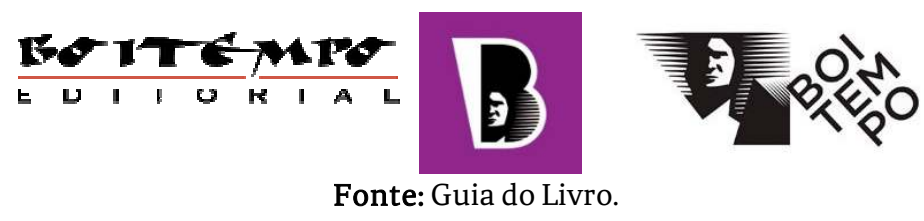

\section{Obras feministas}

Já depois de completar vinte anos, a Boitempo Editorial, em consonância com as discussões de seu tempo, publicou livros eminentemente

\footnotetext{
14 FUKS, Julián. Intelectuais se encontram para esquadrinhar marxismo de Löwy. Folha de S.Paulo, Ilustrada, p. E6, 26 set. 2005.

${ }^{15}$ COZER, Raquel. Folha de S.Paulo, Ilustrada, Painel das Letras, p. C4, 2 maio 2015.

${ }^{16}$ COZER, Raquel. Folha de S.Paulo, Ilustrada, Painel das Letras, p. C4, 12 set. 2015.
} 
feministas ${ }^{17}$. Em 2015, Raquel Cozer noticiava a publicação, ainda futura, de uma importante obra de $1792^{18}$. Tratava-se de Reivindicação dos direitos da mulher, da inglesa Mary Wollstonecraft. Quase um ano depois, na mesma coluna, Maurício Meireles noticiava ${ }^{19}$, enfim, o lançamento do livro. Dizia a nota que o título, considerado precursor do feminismo, fora publicado em 1752 e teria tradução ao português de Maria Lygia Quartim de Moraes. No Guia da Folha de 30 de abril de 2016, Oscar Pilagallo resenhava ${ }^{20}$ a obra e a informação era que a tradução fora de Ivania Pocinho Motta. Em janeiro de 2017, Antonia Pellegrino também resenhava ${ }^{21}$ o título, apontando a importância do texto do século XVIII no contexto das "belas, recatadas e do lar", episódio disparado por uma constrangedora capa da revista $\mathrm{Veja}^{22}$. Em abril de 2017, Maurício Meireles assinava matéria ${ }^{23}$ sobre uma "onda" feminista entre as editoras, que aproveitavam para publicar e republicar obras como as de Judith Butler. A Boitempo era mencionada como a "editora de esquerda" que viu seu Mulher, raça e classe, de Angela Davis, vender mais que o esperado: 14 mil exemplares, quando a tiragem inicial era de modestos 6 mil. A matéria, na verdade, resenhava o livro de poemas da canadense Rupi Kaur, Outros jeitos de usar a boca, publicado pela editora multinacional Planeta.

\section{Literatura}

Não satisfeita em atuar na seara dos livros acadêmicos de esquerda no Brasil, a Boitempo Editorial também teve papel marcante na literatura, fazendo jus ao nome que carrega. Alguns episódios e obras foram particularmente relevantes na história da casa, servindo de mote para

\footnotetext{
17 Para citar duas casas editoriais francamente feministas, mencionamos a editora Mulheres, dirigida principalmente pela professora Zahidé Muzart (Florianópolis, com fundação em 1996) e a Rosa dos Tempos, no Rio de Janeiro, também nos anos 1990, capitaneada em especial por Rose Marie Muraro.

${ }^{18}$ COZER, Raquel. Folha de S.Paulo, llustrada, Painel das Letras, p. E4, 14 mar. 2015.

${ }^{19}$ MEIRELES, Maurício. Folha de S.Paulo, llustrada, Painel das Letras, p. C4, 5 mar. 2016.

20 PILAGALLO, Oscar. Reivindicação dos direitos da mulher. Folha de S.Paulo, Guia da Folha, p. 18, 30 abr. 2016.

${ }^{21}$ PELLEGRINO, Antonia. Atualidade de clássico feminista segue intocada. Folha de S.Paulo, llustrada, p. C5, 3 jan. 2017.

${ }^{22}$ A frase referia-se à então primeira dama, Marcela Temer, esposa do Presidente Michel Temer. De tão inoportuna, capa e matéria da revista tornaram-se piada e meme, nas redes sociais, transformando-se a frase, enfim, em um bordão que acendeu os ânimos feministas.

${ }^{23}$ MEIRELES, Maurício. Do comercial ao "cabeça", editoras do país exploram onda feminista. Folha de S. Paulo, llustrada, p. C4, 8 abr. 2017.
} 
polêmicas e discussões por anos a fio, nas páginas do jornal que nos serviu de acervo de pesquisa.

O início da trilha literária de sucesso da Boitempo contou com a obra Os sobreviventes, terceiro livro do escritor mineiro Luiz Ruffato, considerada uma "ficção sobre pobreza e violência na atualidade", em nota ${ }^{24}$ de janeiro de 2000, quando a editora contava apenas 5 anos de existência. Em 14 de fevereiro de 2001, outra nota informava que Luiz Ruffato recebera menção especial do prêmio Casa de las Americas, em Havana, por esse título. No mesmo ano, o professor Luís Augusto Fischer ${ }^{25}$, na coluna Estante, mencionava Luiz Ruffato e seu "belo e sofrido livro". Como se verifica, a Boitempo continuava alinhada aos seus objetivos e ideologias, mesmo na literatura. Pode-se acompanhar a ascensão de Ruffato como escritor e, em 2005, o lançamento de Infernos provisórios, pela Companhia das Letras, mas sempre mencionando que livros anteriores do autor foram lançados pela Boitempo. Nesse mesmo ano, outras obras, como Eles eram muitos cavalos, passam a merecer a atenção especial da crítica.

Outros brasileiros publicados pela Boitempo também receberam atenção da imprensa. É o caso de João Anzanello Carrascoza, que publicou um conto $^{26}$ no Mais! de 22 de agosto de 2004, sendo já autor do livro de contos Duas tardes, pela Boitempo; e de Edyr Augusto, autor de Casa de cabra, resenhado por Joca Reiners Terron ${ }^{27}$, segundo quem esses lançamentos eram "oportunidade rara de se medir a temperatura da ficção realizada em outras plagas do país" (destaque nosso). Outro livro de Edyr Augusto pela Boitempo, Pssica, mereceu resenhas ${ }^{28}$ do crítico e professor gaúcho Luís Augusto Fischer e do jornalista e escritor paulistano Ronaldo Bressane. Finalmente, no Painel das Letras, o colunista Maurício Meireles noticiava ${ }^{29}$ a venda dos direitos dessa obra para a editora francesa Asphalte, responsável pelo sucesso de Edyr

\footnotetext{
${ }^{24}$ BERGAMO, Mônica. Folha de S.Paulo, Curto-circuito, p. 6, 31 jan. 2000.

${ }^{25}$ FISCHER, Luís Augusto. A difícil tarefa de fazer literatura que retrata a gente miserável. Folha de S.Paulo, Folhateen, Estante, p. 11, 18 jun. 2001.

${ }^{26}$ CARRASCOZA, João Anzanello. A terceira margem de mim. Folha de S.Paulo, Mais!, p. 10, 22 ago. 2004.

${ }^{27}$ TERRON, Joca Reiners. Autores do Norte trazem realismos mágico e trágico. Folha de S.Paulo, llustrada, p. E4, 2 out. 2004. O plural referia-se a O livro dos desmandamentos, de Carlos Trigueiro, pela Bertrand Brasil.

${ }^{28}$ FISCHER, Luís Augusto. Edyr Augusto oferece narrativa assustadora com discurso enxuto. Folha de S.Paulo, Ilustrada, p. C4, 22 ago. 2015 / BRESSANE, Ronaldo. Pssica. Folha de S.Paulo, Guia da Folha, p. 12, 26 set. 2015.

${ }^{29}$ MEIRELES, Maurício. Folha de S.Paulo, Ilustrada, Painel das Letras, p. C4, 31 out. 2004.
} 
naquele país. A Boitempo negociava direitos também com Alemanha, Holanda, Espanha e Itália.

Entre outros lançamentos e autores individuais, inclusive alguns que foram finalistas ou ganharam prêmios importantes, dentro e fora do Brasil, é de se destacar o caso do escritor cubano Leonardo Padura. A partir do lançamento de $O$ homem que amava os cachorros, em 2013, traduzido por Helena Pitta, a Boitempo passou a angariar resenhas como a do escritor e tradutor Joca Reiners Terron para o Guia da Folha ${ }^{30}$. A obra tem uma história de sucesso no país, com vendagem muito acima do esperado pela editora.

O jornalista Fabio Victor fez a cobertura ${ }^{31}$ de um evento com Padura no Sesc Consolação, em São Paulo, onde o cubano participou de um debate com Gilberto Maringoni, Ricardo Lísias e Sylvia Colombo, com mediação de Kim Doria, da Boitempo. O livro foi considerado então um êxito de vendas (12 mil cópias, segundo a editora), tendo sido recomendado por personalidades brasileiras, além de aclamado pela crítica. A obra foi chamada de "antibestseller", já que contava quase 600 páginas e muitos narradores. Na Ilustríssima ${ }^{32}$, o próprio escritor foi autor de um texto de página inteira em que, além de mencionar a Boitempo, narrava seu interesse pelo Brasil e um almoço com a então presidenta Dilma Rousseff. Em julho de 2015, Juliana Gragnani ${ }^{33}$ noticiava Padura como convidado da Festa Literária Internacional de Paraty - Flip, evento mais visível e de alto valor simbólico no Brasil atual. Segundo o texto, o livro $O$ homem que amava os cachorros vendera 50 mil exemplares no Brasil e 8 mil em Cuba. O autor anunciava para setembro o lançamento de outro livro, Hereges, pela Boitempo. Curiosamente, em março de 2014, na coluna de Monica Bergamo ${ }^{34}$, uma nota sobre a falta do livro de Padura na rede Livraria da Travessa, no Rio, narrava um roubo de carga na Via Dutra. Toda a carga de um caminhão cheio de livros fora levada. A Boitempo teria mandado reimprimir 300 exemplares da obra para atender as livrarias

\footnotetext{
30 TERRON, Joca Reiners. O homem que amava os cachorros. Folha de S.Paulo, Guia da Folha, p. 13, 21 dez. 2013.

${ }^{31}$ VICTOR, Fabio. Fazer má literatura é difícil, diz escritor Leonardo Padura. Folha de S.Paulo, llustrada, p. E3, 17 abr. 2014.

32 PADURA, Leonardo. Adivinha quem me chama para almoçar. Folha de S.Paulo, llustríssima, p. 3, 27 abr. 2014.

33 GRAGNANI, Juliana. Maldição persegue os cubanos, afirma Leonardo Padura. Folha de S.Paulo, Ilustrada, p. C3, 5 jul. 2015.

${ }^{34}$ BERGAMO, Mônica. O livro sumiu. Folha de S.Paulo, Ilustrada, p. E2, 20 mar. 2014.
} 
com agilidade. Sobre Hereges, lançado em 2015, houve resenhas de Juliana Gragnani ${ }^{35}$ e de Ronaldo Bressane ${ }^{36}$.

Em 2016, novo romance de Padura foi anunciado pela Boitempo, na Folha. A Ilustríssima ${ }^{37}$ estampava um excerto de página inteira. O romance se chamaria Paisagem de outubro e seria lançado em novembro, juntamente com reedições de três títulos. O lançamento propriamente foi noticiado ${ }^{38} \mathrm{em}$ outubro, divulgando-se também o curso "Para que se escreve um romance?", oferecido por Padura no Centro de Pesquisa e Formação do Sesc. A tetralogia foi novamente anunciada e explicada em matéria de página inteira de Sylvia Colombo ${ }^{39}$.

Mesmo com todo esse sucesso de alguns escritores publicados pela Boitempo Editorial, talvez nada tenha durado tanto quanto a sempre reacesa polêmica sobre antologias de autores contemporâneos. Em setembro de 2001, o professor Luís Augusto Fischer ${ }^{40}$ tratava do lançamento da antologia de contos Geração 90 - manuscritos de computador, organizada por Nelson de Oliveira, apontando a irregularidade de toda antologia, mas também a importância delas para a fixação de um cenário literário, mesmo que incompleto. Para o caso de Geração 90, dizia o crítico que se tratava de um grande esforço, que valia a pena lê-la, mas questionava se ela realmente representava a literatura de uma geração e de um país inteiro. A despeito disso, o tom geral do texto era positivo.

Na Ilustrada de 9 de março de 2002 ${ }^{41}$, Cassiano Elek Machado mencionava a participação do escritor Marcelo Mirisola na antologia Geração 90. Os autores ali presentes passaram então a ser referidos, apesar de todas as críticas, como participantes daquela obra ${ }^{42}$. No ano seguinte, o jornalista Ivan

${ }^{35}$ GRAGNANI, Juliana. Padura investiga judaísmo em "Hereges". Folha de S.Paulo, Ilustrada, p. C4, 23 set. 2015.

${ }^{36}$ BRESSANE, Ronaldo. Hereges. Folha de S.Paulo, Guia da Folha, p, 13, 31 out. 2015.

37 PADURA, Leonardo. Embaixo daquele céu enganador. (Trad. Ivone Benedetti) Folha de S.Paulo, Ilustríssima, p. 10, 9 out. 2016.

${ }^{38}$ nota de 28 de outubro (llustrada, p. C8)

${ }^{39}$ COLOMBO, Sylvia. Tetralogia suja de Havana. Folha de S.Paulo, Ilustrada, p. C1, 9 nov. 2016.

${ }^{40} \mathrm{FISCHER}$, Luís Augusto. Antologias e a desigualdade no panorama das letras de uma geração. Folha de S.Paulo, Folhateen, Estante, p. 11, 10 set. 2001.

${ }^{41}$ MACHADO, Cassiano Elek. Vim do inferno, diz Marcelo Mirisola. Folha de S.Paulo, Ilustrada, p. E1, 9 mar. 2002

${ }^{42}$ Escrevemos sobre a antologia, aprofundando-nos em um de seus autores, o contista Sérgio Fantini, em Ribeiro e Carvalho (2016). 
Finotti assinava matéria ${ }^{43}$ em que Nelson de Oliveira era convocado a responder sobre as críticas que as antologias (àquela altura já duas, Geração 90: os transgressores) sofreram por tentarem enquadrar contistas tão diversos numa "geração". No texto, o escritor Bernardo Carvalho criticava a antologia e o forjamento dessa "geração", enquanto a editora Luciana VillasBoas, ainda na editora Record, e o escritor Fernando Bonassi, além do então escritor iniciante Marcelino Freire, defendiam a antologia e a nomeação geracional como estratégia de marketing. Ao final, a matéria destacava o fato de o primeiro livro ter demorado cerca de dois anos para vender sua tiragem de 3 mil exemplares. Nelson de Oliveira finalizava dizendo que a segunda antologia também levaria, provavelmente, o mesmo tempo para se esgotar.

Num salto para o ano de 2010, pode-se encontrar matéria ${ }^{44}$ do jornalista Fabio Victor, na qual Nelson de Oliveira falava de uma nova antologia: Geração zero zero, pela editora Língua Geral. O episódio, no entanto, revitalizava a polêmica da primeira antologia, pela Boitempo. $\mathrm{Na}$ mesma página ${ }^{45}$, Paulo Werneck, então editor da Ilustríssima, retomava explicitamente o caso das antologias anteriores à zero zero, criticando-as quanto ao critério geracional e ao tom marqueteiro. A contenda teve sequência por mais um ano, quando, em $2011^{46}$, Paulo Roberto Pires e Nelson de Oliveira debateram, em página inteira, sobre as antologias lançadas nos anos 2000. Mais uma vez, o jornal trazia à tona as antologias Geração 90 (manuscritos e transgressores), lançadas pela Boitempo. E elas serviam ainda de mote para que, em 2012 ${ }^{47}$, Luís Augusto Fischer comparasse a badalada revista Granta, que reunia contos de autores brasileiros, a duas antologias anteriores: Os cem melhores contos brasileiros do século, de Ítalo Moriconi (2000), e Geração 90: manuscritos de computador, de Nelson de Oliveira (2001), isto é, uma década depois. Concluía Fischer que a seleção de contos da Granta era mais autorreferente e mais metropolitana do que as antologias brasileiras, um pouco mais diversificadas em termos culturais.

\footnotetext{
${ }_{43}^{4}$ FINOTTI, Ivan. Marketing divulga "Geração 90", mas os livros não vendem muito. Folha de S.Paulo, Ilustrada, p. E3, 16 ago. 2003.

${ }_{44}$ VICTOR, Fabio. Título prenuncia novas controvérsias. Folha de S.Paulo, Ilustrada, Livros, p. E10, 18 dez. 2010.

${ }^{45}$ WERNECK, Paulo. Antologias simbolizam a era do marketing literário. Folha de S.Paulo, llustrada, Livros, p. E10, 18 dez. 2010.

${ }^{46}$ PIRES, Paulo Roberto Pires. A crítica e o vale-tudo. Folha de S.Paulo, llustríssima, p. 7, 21 ago. 2011.

${ }^{47}$ FISCHER, Luís Augusto. Letras em números. Folha de S.Paulo, llustríssima, p. 6, 2 set. 2012.
} 


\section{Coleções}

É comum que, a fim de organizar, dar visibilidade e alinhar seus livros sob algum critério razoavelmente claro, as editoras criem coleções. E não foi diferente com a Boitempo, que conta, até os dias que correm, com livros publicados sob as etiquetas de coleções como "Estado de sítio", "Clássicos Boitempo" ou "Arsenal Lênin", para citar apenas três das onze listadas no site da editora ${ }^{48}$. Dentre tais coleções, criadas ao longo dos mais de vinte anos de atuação da casa, talvez a mais visível tenha sido Pauliceia, amplamente noticiada e resenhada na Folha de S.Paulo, mesmo como coleção. É possível verificar essa visibilidade por meio de resenhas e notícias, reforçadas, anos depois, pela ocasião da comemoração dos 450 anos da capital paulista.

Obviamente, o nome Pauliceia remete ao livro de Mário de Andrade, embora a coleção não seja formada por livros necessariamente literários. Em maio de 2002, os jornalistas Cassiano Elek Machado e Francesca Angiolillo assinaram ${ }^{49}$ matéria que tratou, genericamente, de coleções de biografias que ainda seriam lançadas. Uma delas sairia pela Boitempo: a coleção Paulicéia reuniria perfis de Sérgio Buarque de Holanda, Adoniran Barbosa, da Semana de 22, entre outros. Diziam, muito paulistanamente, os autores da notícia:

É nas editoras, não em institutos geográficos, que se desenha um novo mapa do Brasil. Nesse traçado o que menos importa são fronteiras, rios ou montanhas: quem empresta a cara são os personagens que povoam seus Estados.

Esse mapa não surge de caso pensado. É fruto de uma conjunção editorial que começou, em 1996, com a coleção Perfis do Rio, da Relume-Dumará, que já reúne mais de 30 retratos de cariocas, de nascimento ou adoção.

No Ceará brotou, alguns anos mais tarde, a série Terra Bárbara, conjunto de livros da Edições Demócrito Rocha, que já evoca quase duas dezenas de personalidades da história do Estado.

\footnotetext{
${ }^{48}$ Conferir em <https://www.boitempoeditorial.com.br/>

${ }^{49}$ MACHADO, Cassiano Elek; ANGIOLILLO, Francesca. O Brasil de perfil. Folha de S.Paulo, Ilustrada, p. E1, 2 maio 2002.
} 
Mirando a terra de Castro Alves e Jorge Amado, a coleção Bahia com $\mathrm{H}$, da editora Manati, acaba de lançar seu primeiro título.

É nas pranchetas paulistas, porém, que estão sendo ensaiados os novíssimos contornos dessa geografia. Duas coleções, que começam a ser publicadas no próximo semestre, colocam São Paulo no mapa.

A primeira delas, batizada de Paulicéia, chega às livrarias em setembro. Concebida pela Boitempo, a série não se limita aos perfis de personagens. Retratos de bairros, ensaios breves sobre temas ligados à história paulistana, como a Semana de 22 e a Democracia Corintiana, e até ficções na cidade compõem a coleção.

A ideia veio da síntese, da constatação da paraense Ivana Jinkings, editora da Boitempo, de que o Estado paulista seria o melhor retrato do que é o Brasil. "São Paulo reúne o que há de melhor e pior no país. É a carteira de identidade brasileira", explica a editora, que coordena a coleção em parceria com o sociólogo Emir Sader.

Embora sejam capazes de identificar iniciativas de coleções em outros estados e editoras, os jornalistas e suas fontes terminam por elevar São Paulo e a coleção Pauliceia a um patamar de "identidade brasileira". No mesmo $a 0^{50}$, a Ilustrada trazia matéria de Cassiano Elek Machado sobre a coleção Pauliceia, desta vez com mais depoimentos de Ivana Jinkings, organizadora/editora. Ela explicava que pretendia "resgatar a auto-estima" paulista e paulistana, por meio de textos leves. Para isso, cercara-se de uma afinada equipe de escritores e produtores culturais. O módulo Retratos, com perfis de personalidades, teria ficado a cargo de Luiz Ruffato, àquela altura já vencedor do prêmio da Associação Paulista de Críticos de Arte - APCA pelo romance Eles eram muitos cavalos, lançado primeiro pela Boitempo em 2001, e depois incorporado ao catálogo da Record e da Companhia das Letras.

Na sequência, à medida que as obras da coleção Pauliceia foram sendo lançadas, surgiram resenhas e comentários sobre os livros: Luís Augusto Fischer resenhou ${ }^{51}$ brevemente Semana de 22, apontando paradoxos do evento histórico e elogiando o "bom livro" e a "bela coleção"; em fevereiro,

\footnotetext{
${ }_{50}$ MACHADO, Cassiano Elek. Coleção traz o Yin-Yang de São Paulo, Folha de S.Paulo, Ilustrada, p. E3, 2 maio 2002.

${ }^{51}$ FISCHER, Luís Augusto. Semana de 22, Folha de S.Paulo, Folhateen, p. 11, 1 fev. 2003.
} 
a Ilustrada trazia resenha ${ }^{52}$ de Cassiano Elek Machado sobre o mesmo título. Em 2004, o mesmo jornalista mencionava a coleção Pauliceia, da Boitempo, cujos primeiros títulos haviam sido lançados em dezembro de 2002 e já eram nove, dois anos depois.

\title{
Selos/coleções
}

Atenta aos movimentos do seu tempo e do mercado editorial, em especial no que diz respeito a editais temáticos de compras públicas, a Boitempo também tomou iniciativas na direção de outros nichos, como a literatura infantil e os quadrinhos. No site da editora, os livros para crianças e os quadrinhos não são considerados selos, mas coleções: Boitatá e Barricada.

A coleção Boitatá foi noticiada em 2016, ocupando a capa de uma edição do Guia da Folha ${ }^{53}$. Inaugurava-se uma série para crianças, sob a responsabilidade da editora Thaisa Burani. O jornalista Manuel da Costa Pinto (2016) apontava a Boitempo como uma editora de "perfil combativo", afirmando também sobre a série intitulada Livros para o Amanhã ${ }^{54}$ :

\begin{abstract}
Num momento de selvagem polarização ideológica do Brasil, uma editora que também publica ficção, mas com um catálogo predominantemente composto por pensadores de esquerda (como os brasileiros Leandro Konder e Michael Löwy, o esloveno Slavoj Zizek e os húngaros György Lukács e István Mészáros), lança uma inusitada coleção de livros com conteúdo político voltado para o público infantojuvenil.
\end{abstract}

Na página 20 do mesmo Guia, Cristina Paiva ${ }^{55}$ escrevia sobre “Educação política”, defendendo o fato de que, mesmo em tempos de obscurantismo e conservadorismo, a Boitempo trazia a público uma coleção infantil sobre democracia, ditadura e outros temas normalmente não dirigidos aos pequenos. Dois livros foram inicialmente lançados, com

\footnotetext{
52 MACHADO, Cassiano Elek. Semana de 22 recebe "vaias" outra vez. Folha de S.Paulo, Ilustrada, p. E4, 18 fev. 2003.

53 FOLHA DE S.PAULO. Democratas mirins, Folha de S.Paulo, Guia da Folha, Capa, 27 fev. 2016.

${ }^{54}$ PINTO, Manuel da Costa. "Pepinos emancipados". Folha de S.Paulo, Guia da Folha, p. 4, 27 fev. 2016.

55 PAIVA, Cristina. Educação política, Folha de S.Paulo, Guia da Folha, p. 20, 27 fev. 2016.
} 
promessa de mais dois, para meses adiante ${ }^{56}$, todos reedições de livros espanhóis dos anos 1970.

Quanto à coleção Barricada, dedicada às histórias em quadrinhos, aparecia na Ilustrada de julho de $2014^{57}$, quando o livro da cartunista alemã Franziska Becker seria lançado pela Boitempo. Último aviso, com tradução de Nélio Schneider, inaugurava os quadrinhos na editora. No mesmo dia ${ }^{58}$, noticiava-se também o lançamento de Cânone gráfico - Clássicos da literatura universal em quadrinhos, organizado pelo antologista americano Russ Kick, com tradução de Magda Lopes. Tratava-se também de uma obra de inauguração do Barricada, que trazia adaptações de obras clássicas, a maior parte produzida especialmente para o livro. Ao final da matéria, anunciava-se que a Boitempo produziria outros dois volumes, com a participação de brasileiros. O projeto da editora previa lançamentos para 2015 e 2016. O livro de Becker, em dois volumes, foi resenhado em $2014^{59}$, teve excerto publicado em $2015^{60}$ e nova resenha em $2016^{61}$.

\section{Tecnologias digitais}

Da mesma maneira que a Boitempo Editorial esteve atenta aos conteúdos e temas com que trabalhava, sempre coerente com sua proposta, ela também não perdeu de vista mudanças tecnológicas importantes. Esteve ativa quando a questão era o e-book, conforme noticiou Joselia Aguiar em 2011 ${ }^{62}$. A editora levaria para o formato digital cem títulos, "um terço do catálogo", ao custo de $75 \%$ do valor do livro impresso. Como sempre, os autores de esquerda seriam os primeiros. Em março de 2012, na mesma coluna $^{63}$, a jornalista noticiava o lançamento, em abril, do livro Occupy,

\footnotetext{
${ }^{56}$ Foram: A democracia pode ser assim, de Equipo Plantel, ilustrações de Marta Pina; A ditadura é assim, de Equipo Plantel, ilustração de Mikel Casal (trad. Thaisa Burani); O que são classes sociais?, de Equipo Plantel, ilustração de Joan Negrescolor (trad. Thaisa Burani); e As mulheres e os homens, de Equipo Plantel, ilustração de Luci Gutiérrez (trad. Thaisa Burani).

${ }^{57}$ RAMOS, Paulo. Cartunista alemã ri da vida e do sexo feminino. Folha de S. Paulo, llustrada, p. E5, 5 jul. 2014.

${ }^{58}$ RAMOS, Paulo. Obra reúne clássicos em versões de HQ. Folha de S. Paulo, llustrada, p. E4, 5 jul. 2014.

59 MARRA, Fabio. Livro explora capacidade narrativa das HQs. Folha de S.Paulo, llustrada, p. E3, 15 dez. 2014.

${ }^{60}$ MEIRELES, Maurício. Folha de S.Paulo, Ilustrada, Painel das Letras, p. C4, 21 nov. 2015.

${ }^{61}$ BRESSANE, Ronaldo. Cânone gráfico, Vol. 2, Folha de S.Paulo, Guia da Folha, p. 16, 27 fev. 2016.

${ }^{62}$ AGUIAR, Joselia. Folha de S.Paulo, Ilustrada, Painel das Letras, p. E6, 1o out., 2011.

${ }^{63}$ AGUIAR, Joselia. Folha de S.Paulo, Ilustrada, Painel das Letras, p. E8, 17 mar. 2012.
} 
parceria com o portal de esquerda Carta Maior. Anunciava também a venda do e-book pela metade do preço do impresso, além de um acordo com a Amazon para a publicação da obra digital em inglês. A resenha do livro propriamente, com textos de Slavoj Zizek, Tariq Ali, Vladimir Safatle e outros, apareceu na Ilustrada de 4 de abril ${ }^{64}$.

Na seção Livros ${ }^{65}$, em março de 2012, Fabio Victor noticiava a estratégia de várias editoras: desmembrar livros, a fim de vendê-los mais curtos, em papel ou e-book. O jornalista fazia uma comparação com a indústria fonográfica e o formato mp3. Entre as fontes estava o editor da gaúcha L\&PM, dizendo que esse tipo de estratégia funcionava como degustação das obras de autores, mas que a venda de e-books ainda era muito menor que a de impressos. A leitura em dispositivos móveis era mostrada como uma aposta, e aí o depoimento foi de Kim Doria, responsável pela área digital da Boitempo, mencionada como empresa que reduziu preços de seus ebooks e estudava a venda isolada de artigos de suas revistas. Uma notinha no fim da matéria destacava a casa de Ivana Jinkings por sua política de descontos em e-books (de 50 a $65 \%$ em relação aos impressos), sob o argumento de que isso poderia ajudar a popularizar o formato no Brasil. A editora dizia ter reduzido sua margem de lucro, contando com o apoio dos autores na experiência.

\section{Políticas do livro e da edição}

Ivana Jinkings não se envolveu com seu catálogo e seus autores de maneira isolada. Manteve o espírito “combativo" para defender a bibliodiversidade e o espaço das editoras pequenas e médias no Brasil. Já em $2002^{66}$, a Folha tratava da abertura da Primavera dos Livros no Centro Cultural São Paulo (depois de sua versão carioca, um ano antes), feira relacionada à Liga Brasileira de Editoras, com forte atuação da fundadora da Boitempo. "É a vez das pequenas e médias", anunciava uma notícia sobre descontos, títulos a serem encontrados e a intenção da feira de "oferecer diretamente aos leitores obras que perderam espaço dentro das megastores".

\footnotetext{
${ }^{64}$ LUCENA, Eleonora de. "Occupy" discute dilemas do movimento". Folha de S.Paulo, Ilustrada, p. E3, 4 abr. 2012.

${ }^{65}$ VICTOR, Fábio. Literatura em pílulas. Folha de S.Paulo, Ilustrada, p. E4, 24 mar. 2012.

${ }^{66}$ SUZUKI, Shin Oliva. Por um lugar na estante. Folha de S.Paulo, FolhaAcontece, p. E1, 17 out. 2002.
} 
Ivana Jinkings, então com 40 anos, era a voz convocada na matéria como organizadora e divulgadora da Primavera, representando uma comissão. A feira era justificada como espaço alternativo às grandes livrarias, à espetacularização das bienais, que "estavam deixando o livro em segundo plano". Também era intenção atrair os leitores para os salões, de maneira menos difusa, com uma oferta de livros que não se diluísse entre didáticos e autoajuda. Os estandes seriam padronizados para todas as editoras e não haveria lançamentos com autógrafos, o que faria do livro a atração maior, embora estivessem previstos debates com autores. Sobre a relação conflituosa com livreiros, que viam com maus olhos a venda direta ao consumidor, Ivana dizia que a questão estava resolvida e já havia parcerias. Jinkings anunciava que a Primavera seria anual no Rio de Janeiro e em São Paulo e que ganharia versões em Porto Alegre e Belo Horizonte, a partir de 2003, o que não ocorreu regularmente.

Um ano antes, 2002, Cassiano Elek Machado ${ }^{67}$ relatava a criação da Primavera do Livro no Rio, seu sucesso como alternativa às bienais gigantes, sua expansão para São Paulo, onde teria recebido um público de 12 mil pessoas. Mais adiante, noticiava que as editoras ligadas à Libre haviam conseguido um estande de $800 \mathrm{~m}^{2}$ na Bienal do Livro do Rio. Discutia-se na Libre a participação das "nanicas" e a abertura de uma livraria da associação.

Não apenas a Primavera do Livro esteve em questão. O adiamento de uma feira de livros na USP ganhou destaque à época ${ }^{68}$. Depois de explicar e especular sobre os motivos do adiamento (questões logísticas - 130 expositores não caberiam no local, a FFLCH - e de segurança), o texto convocava as vozes dos organizadores (Edusp) e de alguns editores expositores: Ivana Jinkings (Boitempo), Cassiano Elek Machado (Cosac Naify) e Haroldo Ceravolo (Alameda). As editoras explicitaram suas estratégias ao adiamento: colocar livros com desconto à venda em seus sites. Ivana Jinkings relatava, então, que vendia muito na feira da USP e Ceravolo informava que sua editora, a Alameda, fizera muitas reimpressões apenas para atender ao evento. Cassiano Elek Machado afirmava que a feira funcionava bem para

\footnotetext{
${ }^{67}$ MACHADO, Cassiano Elek. Pequenas crescem. Folha de S.Paulo, llustrada, p. E3, 23 nov. 2002.

${ }^{68}$ COZER, Raquel. Adiamento de feira de livros da USP causa apreensão. Folha de S.Paulo, Ilustrada, p. E9, 25 nov. 2011.
} 
livros acadêmicos, gênero que geralmente não tem destaque nas vitrines de livrarias.

Outras questões sobre o mercado editorial brasileiro estiveram em destaque na imprensa e contaram com a experiência de Ivana Jinkings e sua Boitempo. Carielo, Lima e Simões ${ }^{69}$ assinaram extensa matéria em que Jinkings opinava contrariamente à prática das grandes livrarias, como Fnac, Cultura e Saraiva, de cobrarem pela exposição dos livros nas vitrines ${ }^{70}$. Além de Ivana, foram fontes Ivo Camargo, diretor de vendas da Ediouro, com maior destaque; Luciana Villas-Boas, da Record, dizendo desconhecer a prática; Marcos Pereira, da Sextante, confirmando o modo de atuação das livrarias; Araken Ribeiro, editor da Contracapa e então presidente da Liga Brasileira de Editoras; e Eliana Sá, da Sá Editora. Todos concordavam que a prática era negativa e excluía as pequenas e médias editoras da concorrência por grandes espaços. Ivana defendia que o leitor fosse alertado sobre os livros que estão em espaços pagos, e não são simplesmente indicações espontâneas.

$\mathrm{O}$ resultado de uma enquete da Folha sobre os personagens mais influentes do mercado editorial brasileiro foi publicado no caderno Mais! em $2006^{71}$. Entre os citados, a terceira é a editora Luciana Villas-Boas, então na Record, que defendia o boca-a-boca como forma de divulgação dos livros. Ivana Jinkings fora parte do júri da enquete. Dos 36 jurados, 6 eram mulheres, entre professoras, tradutoras, críticas e livreiras (Bárbara Heliodora, Kathrin Rosenfield, Leyla Perrone-Moisés, Milena Duchiade e Walnice Nogueira Galvão).

Um esforço de manter um espaço diverso e firme para as editoras de menor porte ocorria paralelamente ao trabalho de expansão internacional da Boitempo, especialmente em relação às traduções de autores relevantes, elemento fundamental do catálogo da editora. Em algumas ocasiões, a imprensa noticiou a participação da Boitempo em leilões e compras de direitos de livros estrangeiros, como foi o caso, em 2011, do movimento de exportação da obra Latinoamericana, Enciclopédia contemporânea da

\footnotetext{
${ }^{69}$ CARIELO, Rafael; LIMA, Isabelle Moreira; SIMÕES, Eduardo. Livrarias cobram para dar destaque nas vitrines. Folha de S.Paulo, p. E1, 12 mar. 2006.

${ }^{70}$ Esta prática continua vigente em 2018.

${ }^{71}$ FOLHA DE S.PAULO, Enquete, Mais!, 12 mar. 2006.
} 
América Latina e do Caribe ${ }^{72}$ no México e na Venezuela. O volume já circulava semanalmente no periódico argentino Pagina12.

As participações internacionais da Boitempo podem ser encontradas, em alguns casos, em notas, especialmente na coluna Painel das Letras $^{73}$. No primeiro caso, noticiava-se um seminário pós-Feira de Frankfurt em que editores, entre eles Ivana Jinkings, discutiriam estratégias para venda de livros menos populares, especialmente na área de ciências humanas e sociais. No segundo caso, tratava-se de um evento na Cidade do Cabo, a Assembleia Internacional de Editores Independentes, a ocorrer de 18 a 21 de setembro de 2014. O debate contaria com mais de 85 editores de mais de 35 países, entre os quais estavam Ivana Jinkings (diretora editorial) e Haroldo Ceravolo Sereza, presidente da Libre. Entre os temas estavam o incentivo a pequenas editoras e aos livros digitais.

Mas como nem tudo são flores, ao longo de uma trajetória muito ativa de mais de duas décadas, a Boitempo e Ivana Jinkings enfrentaram alguns percalços, aos quais responderam inclusive por meio da imprensa. A Folha de 13 de novembro de 2006 trazia um pequeno texto de Fernando de Barros e Silva ${ }^{74}$, em que o autor justificava críticas anteriores feitas a Emir Sader, parceiro e sócio de Ivana Jinkings, provavelmente a partir do estranhamento dos leitores do jornal. No texto, Silva identificava Ivana como envolvida em questões políticas e criminais relacionadas a senadores da República e a processos de uns contra outros, por calúnia e difamação. A dupla teria sido "flagrada" pelo político César Benjamin (então vice de Heloísa Helena) fraudando e superfaturando uma licitação para produção do livro Governo Lula: decifrando o enigma, publicado pela Boitempo. No caderno Brasil $^{75}$ de 17 de novembro, Lilian Christofoletti assinava notícia sobre o caso, que culminou no arquivamento do processo de Ivana Jinkings contra César Benjamin por calúnia, difamação e injúria. O motivo era a licitação junto a uma instituição alemã para produção de um livro que a Boitempo teria, segundo Benjamin, superfaturado. O acusado lamentava o fato de o processo

\footnotetext{
72 FOLHA DE S.PAULO. Ilustrada, p. E6, 13 nov. 2011.

${ }^{73}$ AGUIAR, Joselia. Folha de S.Paulo, Painel das Letras, p. E6, 5 out. 2013 / ALMEIDA, Marco Rodrigo. Folha de S.Paulo, 13 set. 2014.

74 SILVA, Fernando de Barros. Decifrando o enigma. Folha de S.Paulo, Opinião, p. A2, 13 nov. 2006.

${ }^{75}$ CHRISTOFOLETTI, Lilian. Folha de S.Paulo, Brasil, p. A9, 17 nov. 2006.
} 
do livro não ter sido investigado. No caderno Opinião ${ }^{76}$ de 18 de novembro, Mariana Setubal esclarecia a questão, defendendo a lisura do processo e informando que a editora Boitempo entrou na licitação e concorreu com a editora de Benjamin, que ofereceria valor mais alto. A Boitempo venceu a licitação, oferecendo custos mais baixos à Fundação Rosa Luxemburgo, e produziu o livro. O acordo teria sido renovado algumas vezes e estaria em pleno funcionamento.

Alguns anos mais tarde, outro episódio peculiar ao mundo editorial trouxe a Boitempo às páginas do jornal: um caso de plágio. No caderno sobre eleições na cidade de São Paulo77, a Boitempo assumia "problemas de tradução" de dois títulos - Considerações sobre o marxismo oriental/Nas trilhas do materialismo histórico, de Perry Anderson, e Lacrimae rerum: ensaios de cinema moderno, de Slavoj Zizek, tendo suspendido a distribuição deles e prometendo restituir o dinheiro, caso leitores preferissem devolver os volumes pelos Correios. O caso havia sido disparado pela tradutora Denise Bottmann, autora da tradução da edição de 1984 do livro de Perry Anderson, pela editora Brasiliense. A denúncia propriamente fora publicada na Folha do dia anterior, enquanto a editora afirmava ter notado o problema em uma conferência interna.

\section{Considerações sobre uma editora viva e brasileira}

Contar, ainda que ligeiramente, a história de uma editora dirigida por uma mulher é tratar da narrativa de sua atuação, propriamente, seu trabalho à frente da casa editorial, especialmente quando a empresa é fundada pelo pulso dessa mesma personagem. Ivana Jinkings vem reafirmando, ao longo das décadas, a coerência de seu catálogo - algo raro nos corre-corres do mercado - e a força de seu selo - confirmando sua visão à esquerda, seus autores, suas obras, sem deixar de observar a mudança e a necessidade de adaptação, a exemplo do que fez quando abriu espaço para obras dirigidas às crianças, às tecnologias digitais e à defesa política e mercadológica dos espaços para editoras como a sua, pequenas, médias e

\footnotetext{
${ }^{76}$ SETUBAL, Mariana. Folha de S.Paulo, Opinião, Painel do Leitor, p. A3, 18 nov. 2006.

77 FOLHA DE S.PAULO. Em nota, editora acusada de plágio de tradução admite "problemas". Eleições, Poder, p. A10, 2 ago. 2012.
} 
brasileiras. Numa análise bourdiana, a Boitempo pode ser vista como uma editora que ganhou "peso" com o passar do tempo (e justo por isso, já que a duração de uma editora diz algo sobre ela), alcançando visibilidade na imprensa, listas de livros mais vendidos, prêmios, autores em júris e fomentos públicos para certas publicações. No contexto brasileiro e ressalvadas as proporções em relação a países europeus, por exemplo, a Boitempo acumulou capital simbólico em um quarto de século, construindo um catálogo de prestígio. O fato de estar sediada na capital financeira do país também concorre para isso, certamente, entre outros laços e capitais menos visíveis a olho nu.

Ainda em seu primeiro quinquênio, o colunista de economia da Folha Paulo Nogueira Batista Jr., autor de $A$ economia como ela é..., narrava como seu livro fora publicado pela $B$ oitempo ${ }^{78}$. Depois de afirmar, discutivelmente, que "é cada vez maior o número de escritores e menor o número de leitores" e que a publicação de livros se trivializara e já não distinguia ninguém, ele escrevia: "acredite, leitor, nem sempre é fácil escrever um livro e assegurar que ele seja editado corretamente". Esse "editado corretamente" é o que nos interessa aqui, já que o colunista explicitava o processo de edição de seu livro, não sem ironia e hostilidade. Vale a longa citação:

Foi um parto difícil. O drama começou com a escolha da editora errada, a Revan, do Rio de Janeiro, que tratou de forma extraordinariamente incompetente e desleixada o meu pobre e indefeso livro. Revi e corrigi as provas durante meses e meses. A editora cometia e repetia uma montanha de erros, misturava arquivos, alterava o texto sem avisar o autor. Quase me levou à loucura.

Um exemplo cômico foi a insistência em trocar a expressão rodriguiana "idiotas da objetividade" por "idiotas da juventude", algo que poderia me incompatibilizar com toda uma nova geração de leitores. Por alguma razão misteriosa, o erro era corrigido e aparecia em provas subsequentes, quem sabe se por alguma auto-referência inconsciente da jovem equipe da Revan.

Depois de meses de desacertos e adiamentos, briguei com a editora e a publicação voltou à estaca zero. Alguns

\footnotetext{
${ }^{78}$ Batista Jr., Paulo Nogueira. Um livro. Folha de S.Paulo, Dinheiro, p. B2, 9 nov. 2000.
} 
amigos, solidários com minhas agruras, se prontificaram a me ajudar a encontrar uma boa editora. E, lá do céu, vendo que eu já havia padecido o bastante, Deus resolveu finalmente me colocar no caminho certo.

Conheci a Ivana Jinkings, dona da Boitempo Editorial, que se interessou imediatamente pelo trabalho. A Ivana era a editora ideal para um autor traumatizado. Cuidou pessoalmente do livro, com carinho e dedicação.

A troca de editora atrasou a publicação mais alguns meses. Mas valeu a pena. O livro foi reestruturado e submetido a novas atualizações e revisões. Aproveitei para incluir material novo de pesquisa, ainda inédito, que ficara pronto nesse meio tempo.

Graças à Ivana, o livro ficou uma beleza. Foi tudo checado e rechecado, nos mínimos detalhes. A uma certa altura do trabalhoso processo de revisão e correção, a Ivana comentou: "O pior é que ninguém vai reparar nesse cuidado todo que estamos tendo".

O trecho explicitava não apenas uma comparação entre casas editoriais, mas também o cuidado com que a Boitempo teria produzido a obra do colunista. A própria Ivana Jinkings era citada, aparecendo aí como profissional da edição no sentido curatorial do texto, e não apenas como publisher ou empresária. Era o perfil da editora que "põe a mão na massa", que conduz o processo de edição e sabe o que está fazendo, levando a cabo a ideia de que o livro não seja um produto qualquer. Esse perfil alinha-se ao que Bourdieu (2018[1999]) descreve como um tipo de editor capaz de frear o "deslizamento em direção ao polo comercial", mantendo o tônus de autonomia e resistência.

É claro que, com uma trajetória como a da Boitempo, foi preciso encontrar reforços. Em $2004^{79}$ noticiava-se "mudança de peso no mercado editorial paulistano": o editor Aluizio Leite Neto, que atuara na Editora 34 por dez anos, mudava-se para a Boitempo. E assim um corpo sólido foi sendo erigido, também pelas parcerias com autores, tradutores, editores, imprensa, etc., sem perder a flexibilidade necessária a uma editora que atravessa as décadas sem perder a personalidade. De acordo com Bourdieu (2018[1999]), há um certo modo de existir e atuar das editoras pequenas e mesmo médias, em especial as que são fundadas e/ou dirigidas por mulheres. Mais que isso, o

${ }^{79}$ MACHADO, Cassiano Elek. Folha de S.Paulo, Ilustrada, Entrelinhas, p. E4, 3 abr. 2004. 
sociólogo considera mesmo que tais editoras geralmente estejam sob o pulso delas, como é o caso de Ivana Jinkings e sua Boitempo Editorial, um caso relevante para a história editorial brasileira.

\section{Referências}

BOURDIEU, Pierre. Uma revolução conservadora na edição. Política \& Sociedade, v. 17, n. 39, p. 198-249. mai./ago. 2018. [Trad. Luciana Salazar Salgado e José de Souza Muniz Jr. Originalmente publicado em Actes de la recherche en Sciences Sociales, v. 126-127, p. 3-28, mars 1999.]

HALLEWELL, Laurence. O livro no Brasil. Sua história. Trad. Maria da Penha Villalobos, Lólio Lourenço de Oliveira e Geraldo Gerson de Souza. 2 ed. São Paulo: Editora da Universidade de São Paulo, 2005.

PIRES, Paulo Roberto. A marca do Z. A vida e os tempos do editor Jorge Zahar. Rio de Janeiro: Zahar, 2017.

RIBEIRO, Ana Elisa; CARVALHO, Rafael F. Elementos para uma aproximação à prosa realista contemporânea de Sérgio Fantini. Scripta, PUCMinas, v. 20, n. 39, p. 197-213, 2016.

SAPIRO, Gisèle. La sociología de la literatura. Ciudad Autónoma de Buenos Aires: Fondo de Cultura Económica, 2016.

THOMPSON, John B. Mercadores de cultura. O mercado editorial no século XXI. Trad. Alzira Allegro. São Paulo: Editora da Unesp, 2013.

Recebido em 29 de abril de 2019.

Aceito em 30 de maio de 2019. 